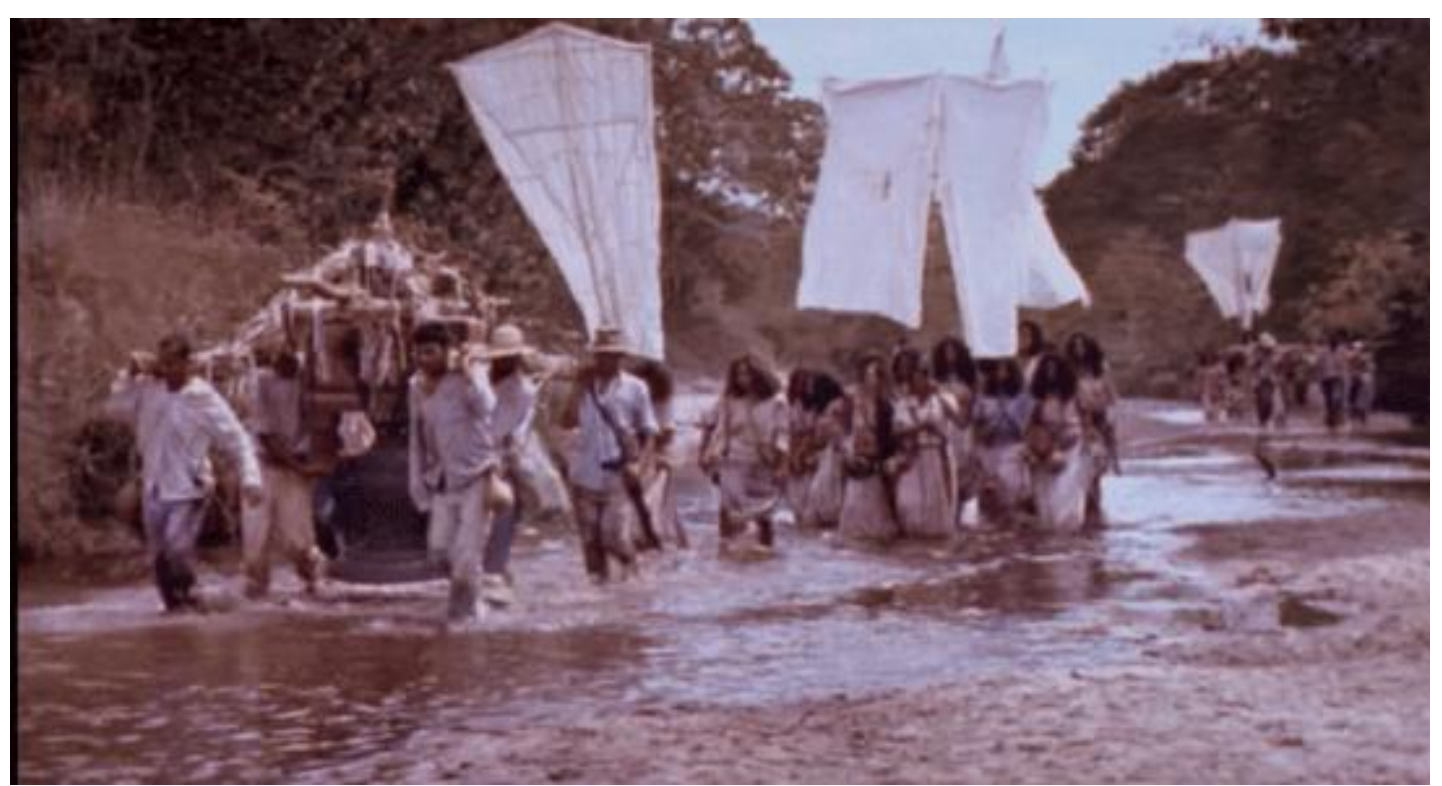

\title{
Imagi-nando multiplicidades entre-tempos/lugares: um olhar sobre o filme Narradores de Javé
}

(Imaging multiplicity between places/time: a perspective about the film Narradores de Javé)

\section{Resumo}

Giovana Scareli*

Este artigo apresenta algumas reflexões a partir do filme Narradores de Javé da diretora Eliane Caffé. O filme foi explorado a partir de uma idéia de pensá-lo em camadas com o objetivo de trazer suas potências de reflexões sobre cinema, educação visual, filosofia entre outras áreas do conhecimento. O texto está organizado em quatro momentos: o filme, mitos, memória e esquecimento, apostando nas diferentes possibilidades de pensar o filme relacionando-o a cada uma dessas palavras/forças.

Palavras chave: Narradores de Javé; cinema; memória

\section{Abstract}

This article presents some reflections from the film of Narradores de Javé by Eliane Caffé. The idea was exploring the movie through layers in order to bring its contribution about cinema, visual education, philosophy and other areas of knowledge. The text is organized in four mainly aspects: the movie, myth, memory and forgetting, investing in different possibilities for thinking the film regarding to each of these words/strengths.

Keywords: Narradores de Javé; cinema; memory

\footnotetext{
* Doutora em Educação pela Universidade Estadual de Campinas (Unicamp). Professora do Programa de Pós-Graduação em Educação da Universidade Tiradentes (Unit). Endereço postal: Rua Euclides Paes Mendonça, 338 - 13 de Julho - Aracaju/SE. E-mail: gscareli@yahoo.com.br
} 


\section{Introdução}

Narradores de Javé (2003), da diretora Eliane Caffé, assim como tantos outros filmes bons, pode ser interpretado de muitas formas. Muitas pessoas "usaram" este filme em uma proposta de trabalho ou uma discussão completamente diferente da outra. Assim, em termos de conteúdo, podemos extrair deste filme uma série de temas que poderiam suscitar muitas discussões. Como, por exemplo: contação de histórias, homenageando os contadores de histórias, os contadores de causos; o direito à terra, o acesso à terra, um direito que é continuamente usurpado por outras formas de relação com a terra; a importância da escrita, a escrita como forma de diferenciação, de construção de conhecimentos; a importância da oralidade como um meio de resgatar a história e transmiti-la aos demais, às próximas gerações; a importância da documentação como garantia de posse, de legitimidade; a importância da história, história cultural, de um povo, de suas raízes, da sua constituição como pertencentes àquele lugar.

Dessa forma, penso que o filme Narradores de Javé traz discussões muito interessantes em termos de conteúdo, principalmente no que diz respeito à relação com a importância da história, da escrita, da documentação... No entanto, o filme também apresenta outra força que é sobre um lugar e um tempo perdido no meio das águas... quase uma Atlântida... quando morrerem aqueles moradores, que de lá saíram, tudo irá virar lenda.

Outro viés é sobre o próprio cinema. O filme apresenta imagens, imagens de um lugar, de pessoas, de cenários que nos dizem ser o Nordeste, região que se apresenta com uma cara, com um sotaque, com uma luz, com pobreza e limitações... também uma lenda, de certo modo, para quem é do Sul-Sudeste do país e nunca morou nesta região. Roberto Machado ao se referir aos estudos de Deleuze irá dizer "o cinema é uma forma de pensamento. Os grandes cineastas são pensadores, embora não pensem conceitualmente, mas por imagens" (2009, p.247).

Eliane Caffé, na abertura do filme, brinca com um dos conteúdos mais importantes e destacáveis do filme: a questão da escrita, do uso das palavras. Há uma brincadeira com as letras que formam os nomes dos atores e demais profissionais que trabalharam no filme, letras se juntam, dançam, formam palavras, nomes e depois se dissolvem, desaparecem... beleza de um trabalho artesanal que pensa com imagens.

O objetivo deste artigo é pensar com/sobre o filme Narradores de Javé, desvelando o filme em camadas, que são potências para outras reflexões sobre cinema, 
educação, filosofia, literatura. O texto está organizado em quatro momentos: o filme, mitos, memória e esquecimento. Penso que há muitas relações entre esses quatro elementos escolhidos como subtítulos e é assim que pretendo conversar com o leitor.

\section{O filme}

É possível pensar que há três camadas diferentes neste filme. Esta idéia de desvelar um filme, de encontrar círculos concêntricos, nos permite relacionar sua construção cinematográfica ao seu conteúdo. Este modo particular de procurar camadas em um filme utilizei em minha tese de doutorado (SCARELI, 2009) com o intuito de

(...) olhar para o filme Santo Forte, propondo-se a trabalhá-lo em camadas. Para isso, buscamos no interior do filme, elementos técnicos e narrativos que o compõem, com o intuito de refletir sobre algumas questões potenciais presentes em cada camada, que revelam construções de diferentes sentidos atribuídos pelo diretor e sua equipe ao conjunto exposto pelo filme (p.3).

Da mesma forma, Narradores de Javé possibilita este modo de entrar no filme, pois apresenta uma construção que permite esse tipo de relação. Assim, a primeira camada de filme é aquela que aparece no início. Um rapaz que perde o barco e precisa esperar até o próximo horário, até a embarcação retornar. Ele aguarda em um bar, na beira do rio onde se encontram outras pessoas. Fala poucas palavras e ouve uma longa história que um dos homens conta. Neste momento, um outro filme entra e toma conta da tela. Trata-se da história do Vale de Javé. O homem que conta a história foi um morador desse local inundado pela construção de uma represa.

O filme se concentrará, em sua maior parte, nesta segunda camada. A história de um povo. Aqui, os diversos temas elencados acima estarão em movimento. A defesa da continuidade da cidade e da permanência de seus moradores depende de um documento que afirme que aquele local é "patrimônio" e, sendo assim, ninguém poderá mexer. No entanto, para que algo adquira esta chancela (de patrimônio), é preciso provar cientificamente a importância daquele local. Este discurso é o pontapé inicial para a estratégia montada para criar um dossiê que mostre a importância deste lugar e de seu povo. Tem início um trabalho dentro do filme que poderíamos chamar de "método científico". O documento deverá ser construído a partir dos conceitos da História Oral. A metodologia se dá através de entrevistas com as pessoas mais velhas do povoado, que, provavelmente, sabem da brava história deste povo. Um "pesquisador", o mais 
"sabido" do povoado - porque era alfabetizado, portanto sabia ler e escrever - ouvirá os relatos e, fazendo uso da escrita, colocará cada palavra em um livro.

A cidade, composta por analfabetos, tinha apenas um morador, um renegado da cidade, que poderia ajudar. Desse modo, outros temas são suscitados: o problema do analfabetismo e do analfabetismo funcional, a importância da escrita como recurso não só da linguagem, não só como uma habilidade, mas como forma de comunicação, escrita com a finalidade argumentativa para "salvar" um povo.

Nesta busca pelos moradores que poderiam contar a história do povoado, outra camada de filme entra em cena. A história que essas pessoas contam e se colocam como os personagens fundadores do Vale de Javé. Novos temas nos são possibilitados: uma necessidade de se mostrar importante, uma forma de sair de uma vida tão simples e pacata e se tornar um bravo guerreiro/guerreira, alguém admirável em seu povo.

\section{Mitos}

Nesta terceira camada, temos quatro mitos ou lendas da fundação de Javé contados pelos personagens Vicentino, Deodora, Firmino e pelo Pai Cariá.

Vicentino apresenta um homem de nome "Indalécio" que conduz seu povo para recobrar as terras que, por direito, eram deles. A história contada é de bravos guerreiros e a imagem deste homem destemido se aproxima de São Jorge. A história é vitoriosa, mostrando a bravura deste povo guerreiro, do qual ele é descendente direto.

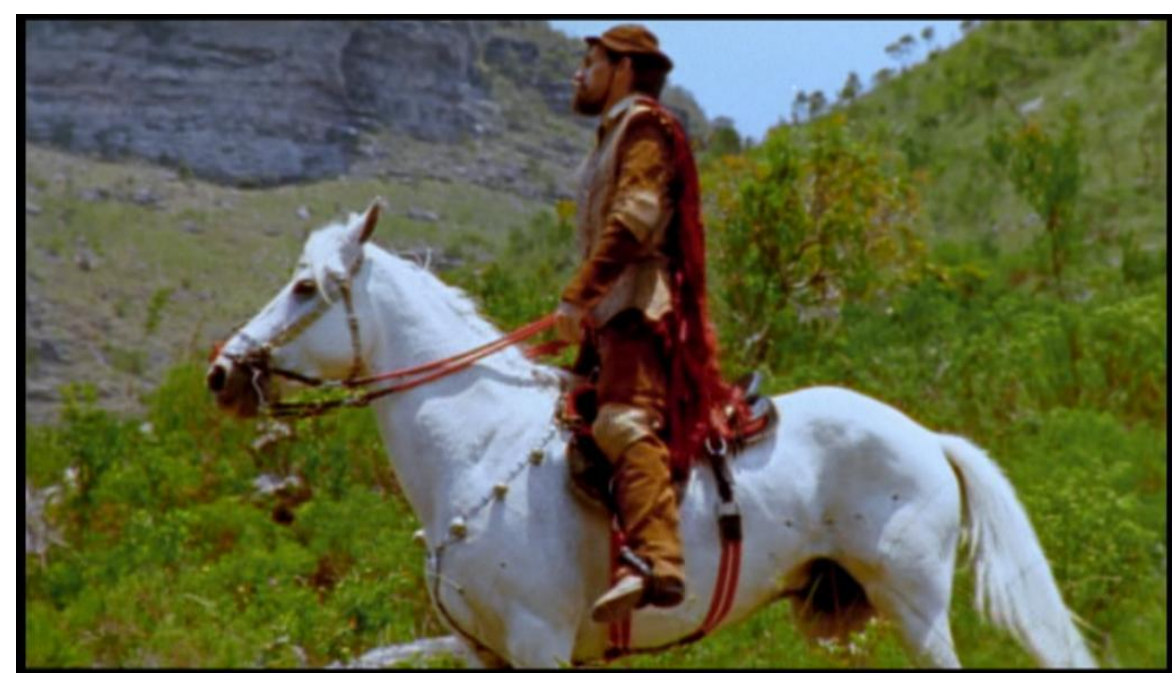

Figura 1 - Imagem de Indalécio contada por Vicentino.

Para Deodora a história é um pouco diferente. Segundo esta personagem, Indalécio morreu durante a busca por Javé e é Mariadina que irá conduzir o povo. Ela 
desapareceu durante um dia e uma noite e os pássaros a mostraram onde era o local ideal. Chegando lá, “cantaram” as divisas de Javé. A imagem de Mariadina é a mesma de Deodora. A história aqui também é vitoriosa e mostra o papel importante da mulher neste lugar.

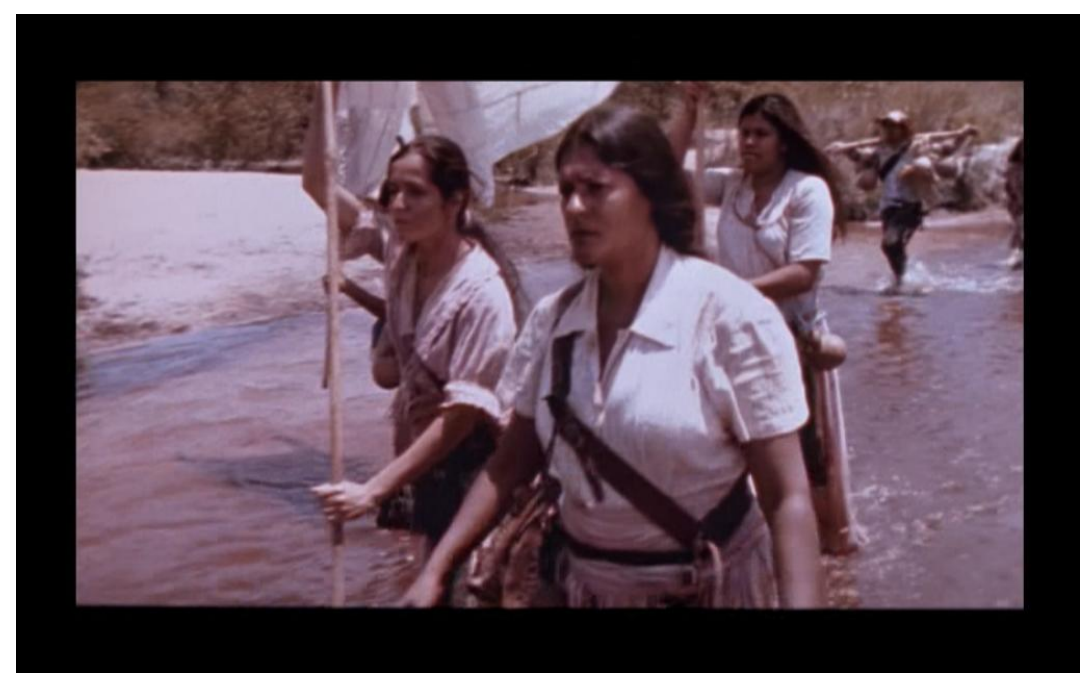

Figura 2 - Imagem de Mariadina contada por Deodora.

A terceira história é de Firmino, que contraria Vicentino e Deodora, pois eles têm interesses em contar dessa forma, já que se julgam descendentes dos "fundadores" do povoado. Assim, a história de Firmino é uma paródia das outras, cheia de aspectos místicos e cômicos. Firmino também se apropria de várias palavras que as pessoas foram dizendo à medida que as histórias eram contadas, ou seja, sua versão traz um conjunto de palavras e imagens das outras histórias. Em sua versão, Mariadina é uma louca que Indalécio encontra no caminho e, antes de encontrar Javé, Indalécio sofre de dor de barriga, cuja disenteria o acaba matando. A imagem de Indalécio é a do próprio Firmino. 


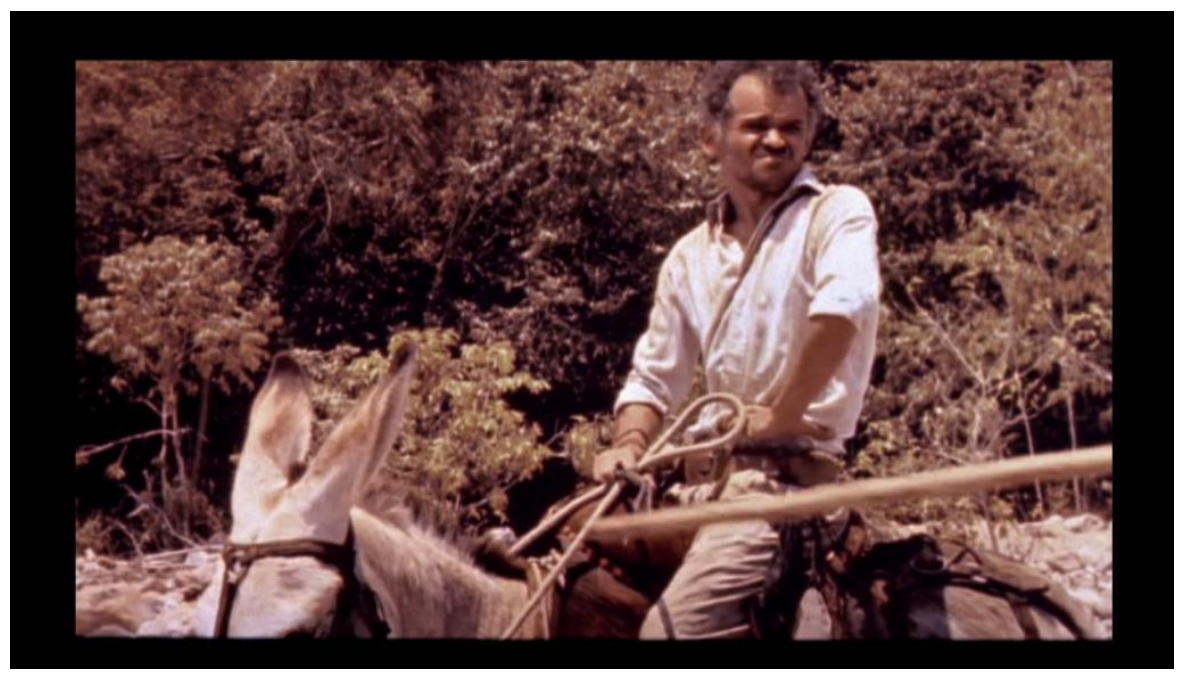

Figura 3 - Imagem de Indalécio contada por Firmino.

A última versão é contada por Pai Cariá, que se encontra em um quilombo, razoavelmente distante do povoado de Javé. Esta versão é contada em iorubá e traduzida por Samuel, outro personagem que conduz Antonio Bia até o quilombo. Nesta história, "Indaleu", não mais Indalécio, é um negro, forte, que conduz seu povo (composto por negros) em busca da terra ideal. Encontram uma cachoeira que era a casa de Oxum e o local onde deveriam permanecer, pois, segundo Pai Cariá, “a África agora estava ali com eles" (ABREU; CAFFÉ, 2004, p.134). A imagem que vemos é de um negro jovem e forte, talvez, a imagem de Pai Cariá quando moço ou ainda a imagem que gostaria de ter.

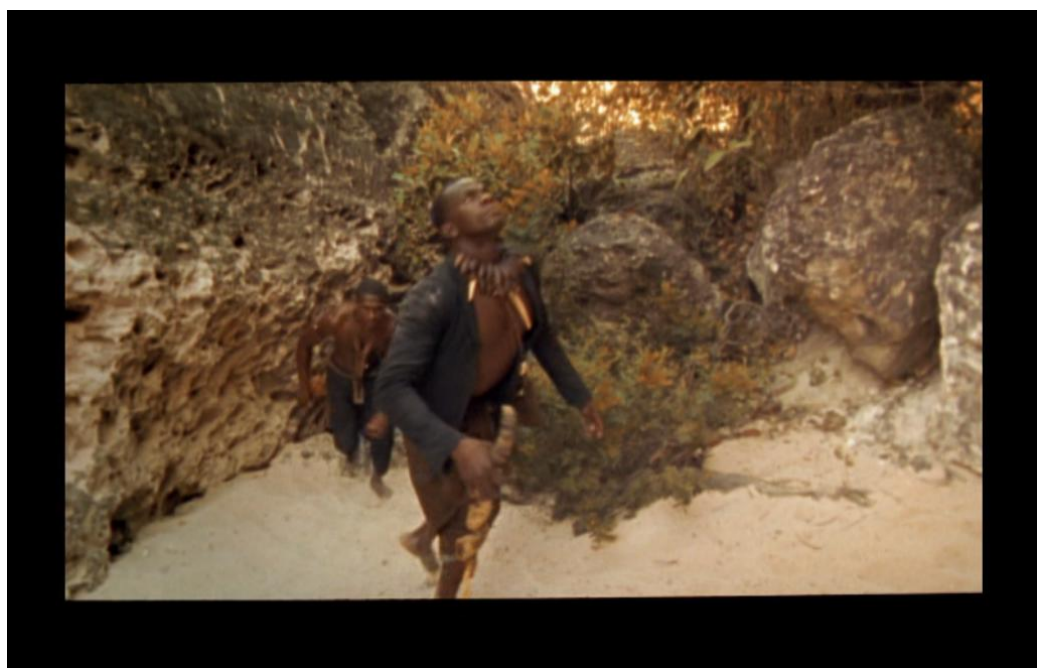

Figura 4 - Imagem de Indaleo contada por Pai Cariá 
Temos aqui várias versões para a mesma história. A coleta desse material se aproxima da metodologia da História Oral, que busca, através dos relatos e narrativas do povo, reconstruir a história.

Ao construir uma representação social da realidade, o imaginário passa a substituir-se a ela, tomando o seu lugar. O mundo passa a ser tal como nós o concebemos, sentimos e avaliamos. Ou, como diria Castoriadis, a sociedade, tal como tal é enunciada, existe porque eu penso nela, porque eu lhe dou existência - ou seja, significação através do pensamento (PESAVENTO, 2006, p.3).

Assim aconteceu com os personagens do filme que, durante as narrativas, traziam uma determinada realidade, imaginada, sonhada, desejada e que, legitimavam e dava importância àquele povo e ao local onde viviam, ameaçados por uma inundação prestes a acontecer. Por alguns instantes, davam existência e significado às suas vidas, através do pensamento, da imaginação, do desejo.

Fábulas, lendas, mitos nos são trazidos por seus moradores e por Eliane Caffé. Mito do nascimento de um mundo, e alguns referenciais são feitos à mitologia. As lendas da criação de um povo, com diferentes versões, lembram os contos populares, maravilhosos, de fadas, que eram transmitidos de geração para geração à beira do fogo. Neste filme, um círculo também se faz no bar para ouvir o contador de histórias.

$\mathrm{O}$ mito do nascimento é sempre uma potência. Diferentes povos explicaram, à sua maneira, como o mundo teve início. Neste filme, também podemos inferir uma referência a este mito quando alguns personagens se reúnem em um bar, próximo ao rio, onde um rapaz chega instantes após a partida da embarcação que precisava pegar. Esta embarcação me remete à história bíblica de Noé, que agrupou um casal de cada espécie de animais que havia na Terra para continuar a vida após o dilúvio. Algo semelhante irá acontecer com os moradores de Javé, terão que se reunir e fugir das águas que inundarão suas casas, sua terra para continuar a vida em outro lugar.

Estamos diante das fabulações de um povo que precisa se tornar heróico na tentativa de salvar aquele lugar e o seu modo de vida. Seria uma espécie de Atlântida, com um povo bravo e inteligente que se perdeu submerso as águas, neste caso do progresso, no entanto, um povo que até aquele momento, não havia precisado justificar sua legitimidade e, talvez por isso, não reconhecesse suas especificidades.

Fabulações que acontecem nas três camadas de filme, que, no entanto, apresenta-se apenas como um filme. O mesmo espaço da tela apresenta filmes distintos; 
tempos diferentes se unem na duração de uma hora e quarenta minutos. Multiplicidades de tempos/lugares no espaço da tela/duração do filme.

\section{Memória}

Segundo Alexandre Werneck, "Narradores é um filme importante para o cinema brasileiro, por jogar de maneira (raramente) inteligente com alguns clichês de nosso cinema contemporâneo, sobretudo com um dos maiores deles, o filmar o Nordeste."

(...) o que talvez mais chame a atenção em Narradores de Javé é seu desejo de eternidade. Ao se esgueirar por ali por fora do histórico, pelo campo do mítico, quase do fabular, do fabuloso, o filme joga com passado e futuro não só na narrativa (como já dissemos), mas também em suas próprias ferramentas expressivas. Poucos filmes atuais (não apenas brasileiros) fazem esse trânsito tão bem. Nisso, compõem-se bem o Nordeste de Graciliano que pulsa como fantasma nos tipos e no chão árido do filme... (WERNECK, 2010, p. 1).

A memória que Werneck trata aqui é "uma memória mítica, é verdade, onde encontra-se com seu segundo assunto, a fala. A memória é feita na fala, é produzida pela narração". Neste filme, memória e oralidade são confrontados com a escrita.

O filme mostra a memória dinâmica e não como algo guardado em uma "caixa secreta", em um baú, como costumamos dizer e que, em algum momento, é resgatada. Acredito que a memória é trabalho, como diz Ecléa Bosi (1999) e é imaginação, como mostram os narradores de Javé. Memória: lembrança e esquecimento; memória: trabalho de criação em função do presente.

Para Gagnebin (1999),

A lembrança do passado não mede, como em Proust, a distância entre a imagem ideal e a realidade decepcionante, uma distância que somente a obra de arte conseguiria abolir. A lembrança do passado desperta no presente o eco de um futuro perdido do qual a ação política deve, hoje, dar conta. Certamente, o passado já se foi e, por isso, não pode ser reencontrado "fora do tempo", numa beleza ideal que a arte teria por tarefa traduzir; mas ele permanece definitivamente estanque, irremediavelmente dobrado sobre si mesmo; depende da ação presente penetrar sua opacidade e retomar o fio de uma história que havia se exaurido. Exatamente como o passado é atravessado pelos signos "que o futuro esqueceu na nossa casa", assim também o sujeito desta história sempre é, ao mesmo tempo, a criança perdida, o adulto preocupado de hoje e o desconhecido de amanhã (p. 89).

O filme Narradores de Javé abre esta possibilidade de pensamento. Eles dependem de uma lembrança de um passado idealizado como possibilidade de garantir 
um futuro sob ameaça. A ação presente, que é também política, tenta salvar um modo de vida conhecido, da desconhecida vida futura.

Para Bergamaschi (2010), os personagens passam então a realizar um trabalho de memória, evocando lembranças, imaginando um passado épico, uma "história grande" do Vale de Javé, com heróis forjados e requisitados pelos homens - Indalécio e pelas mulheres mais ousadas - a Mariadina.

Alguns elementos participam dessa construção narrativa provocando lembranças, reminiscências... Podemos citar, como um elemento mítico fundante, o sino. Em todas as histórias narradas no filme, o sino aparece como o símbolo deste povo que anda a procura de sua terra prometida. Seguem pistas de vários tipos, sempre com mistérios que só o líder pode compreender. “O povo de Deus no deserto andava...” Uma letra de música me vem à memória... O povo de Javé, assim como o povo de Deus, andava muito à procura desta terra especial, prometida. $\mathrm{O}$ sino segue e cada contador $\mathrm{O}$ carrega com os meios de transporte que imagina/possui. Primeiro o sino é transportado em um carro de boi, depois em um andor e por último em um carro. Progresso, evolução dos meios de transporte que também evidenciam o processo da tecnologia que constrói barragens para produção de energia elétrica e para isso inunda o povoado e sua obras, suas memórias. Entretanto a memória é resgatada pelas histórias, ou, parcialmente resgatada.
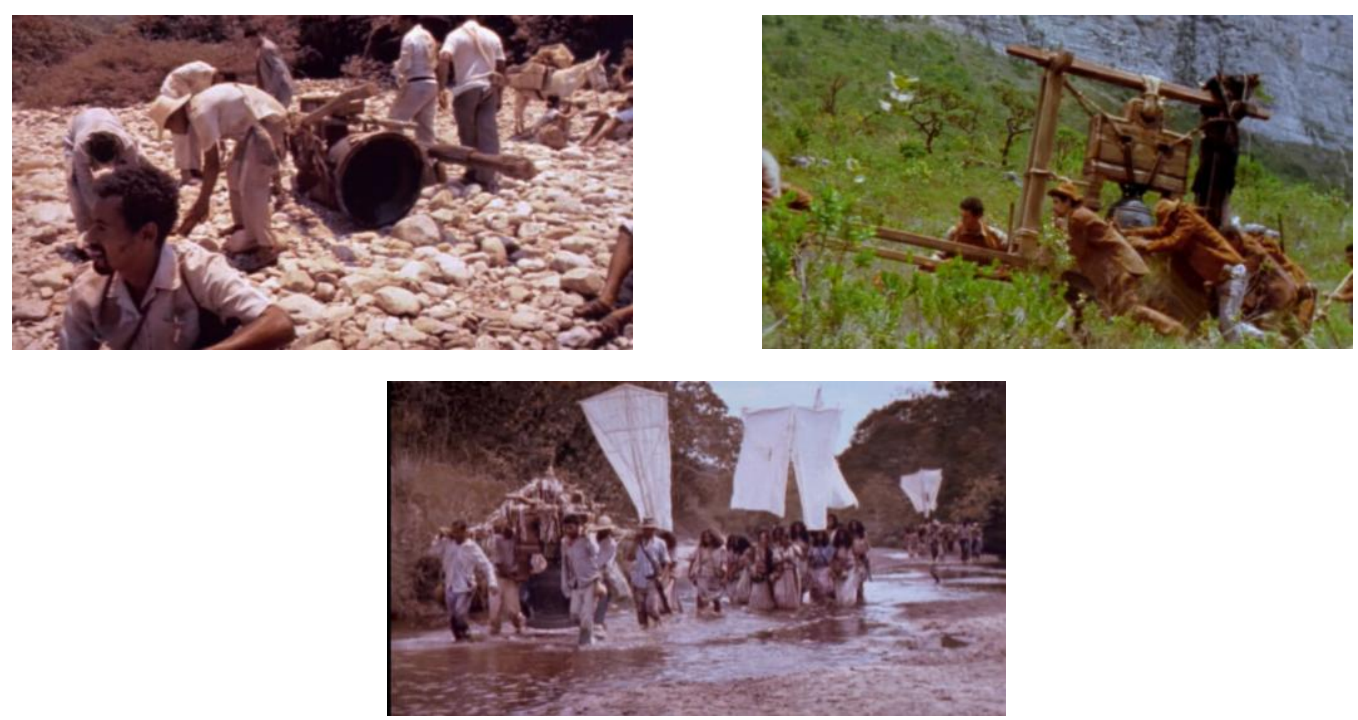

Figura 5, 6, 7 - Imagens do sino

Acredito que é importante dizer que história e memória são construções e ocorrem num campo de disputas como bem mostra o filme, em que cada família, cada 
morador tem a sua versão, constrói um passado para Javé, a partir de seus interesses pessoais e familiares. A memória, assim como a história, não é neutra.

Memória para os gregos antigos era Mnemosyne, filha de Urano (o céu) e Gaia (a Terra). Com Zeus Mnemosyne gerou nove filhas, as musas, responsáveis pela inspiração. Entre elas Clio, a musa da história. A memória é constituída a partir do presente e tem como função principal manter a coesão do grupo, identificando-os como uma "comunidade de memória", produzida, criada, como mostram as narrativas dos moradores de Javé. No filme, cada pessoa, especialmente as mais velhas, requer para si o papel de guardiã da memória e o passado épico é recriado como estratégia de luta, para manutenção da terra diante da ameaça concreta de inundação provocada pela construção de uma barragem.

Uma outra relação com as camadas que podemos considerar diz respeito à própria construção do cinema. Camadas que podem ser expressas pela escrita, oralidade e imaginação. $\mathrm{O}$ filme nos apresenta isso ao tratar da importância da oralidade para que se possa documentar de maneira escrita a imaginação de um povo. Imaginação que pode conter aspectos de realidade. No entanto, estas camadas operam também com o espectador e operam na construção do próprio cinema - primeiro a imaginação, depois a escrita, depois a palavra falada pelos atores, depois a imaginação dos espectadores. Polissemia da imagem cinematográfica e suas potências de pensamento.

Camadas de luz e cores que também marcam diferenças - luz "normal" no bar, entardecer, anoitecer... luz brilhante para os dias de Javé, e tons de sépia para as histórias contadas.

\section{Esquecimento}

Como tratamos de cinema, de memória, de história... enfatizamos a importância dessa lembrança, desse resgate da história, gostaria de tratar de algo que também está relacionado à memória - o "esquecimento". Qual será sua função? Seu papel?

A poesia "Louvor do esquecimento", de Bertold Brecht (s/d) pode nos ajudar a pensar sobre esta faculdade: esquecer.

\section{Louvor do esquecimento}

Bom é o esquecimento.

Senão como é que

O filho deixaria a mãe que o amamentou?

Que lhe deu a força dos membros e

$O$ retém para os experimentar. 
Ou como havia o discípulo de abandonar o mestre

Que lhe deu o saber?

Quando o saber está dado

$\mathrm{O}$ discípulo tem de se pôr a caminho.

Na velha casa

Entram os novos moradores.

Se os que a construíram ainda lá estivessem

A casa seria pequena de mais.

$\mathrm{O}$ fogão aquece. O oleiro que o fez

Já ninguém o conhece. O lavrador

Não reconhece a broa de pão.

Como se levantaria, sem o esquecimento

Da noite que apaga os rastos, o homem de manhã?

Como é que o que foi espancado seis vezes

Se ergueria do chão à sétima

Pra lavrar o pedregal, pra voar

Ao céu perigoso?

A fraqueza da memória dá

Fortaleza aos homens.

O que seria de um povo que teve de deixar seu "lugar", sua "terra prometida" se não fossem as benesses do esquecimento? O tempo é aliado do esquecimento. Esquecimento que se faz lembrado com imaginações. Lapsos de memória que o tempo não conseguiu apagar se alia a capacidade criativa e imaginadora e refaz, recria histórias. Estamos falando de cinema. O cinema lembra e esquece o tempo todo. É apagado, guardado em latas, caixas, baús, reféns da lembrança e/ou do esquecimento.

Para Almeida (1999),

Em todos os gêneros, mesmo em seu gênero 'cult, artístico, intelectual', o cinema e, também, a televisão, revelam-se uma arte da memória e seus trajetos originários enlaçam, num certo momento da história, o Ad Herennium e participam da memória coletiva, histórica. São, também, parte da retórica da indústria e da cultura audiovisual. Ritualizam, em imagens agentes, visuais e sonoras, as imagens e locais que os espectador-fiel deve recordar ao cogitar o passado, o presente e o futuro de sua vida (1999, p. 50) (grifos do autor).

O cinema como arte da memória se mostra neste filme como memória produzida pelo cinema. Memória que é trazida pelos moradores através de suas narrativas. Memória inventada pela diretora do filme, que se torna verdade no tempo da projeção e nas nossas memórias de cinema ao relembrar Narradores de Javé. Memória que se desdobra, que também está nas dobras da linguagem cinematográfica. 
O cinema, ao mesmo tempo, cria ficção e realidades históricas, em imagens agentes e potentes, e produz memória. Uma arte (no sentido atual) ao mesmo tempo um artifício. Artifício que produz conhecimento real e práticas de vida. Grande parte do que as pessoas conhecem hoje e entendem como verdadeiro, só o conhecem por imagens visuais e verbais. Pense, também, na grande parte da população que, sem ter a tradição do conhecimento pela leitura e escrita, passaram para a sociedade ágrafa atual, de comunicação e conhecimento audiovisual (ALMEIDA, 1999, p. 50).

Narradores de Javé é um desses filmes que cria realidades históricas. Será que o Vale de Javé foi "encontrado" da forma como contam seus moradores? Será que Javé existiu? Se isto aconteceu de fato, não importa. Importa que as imagens criadas pelo cinema de Eliane Caffé já fazem parte da nossa memória. São imagens agentes, imagens potentes que potencializaram conhecimentos, reflexões, interpretações. Fazem parte, agora, da nossa memória audiovisual.

\section{Bibliografia}

ALMEIDA, Milton José de. 1999. Cinema arte da memória. Campinas, SP: Autores Associados.

BERGAMASCHI, Maria Aparecida. Narradores de Javé: a memória entre a tradição oral e a escrita. Disponível em: 〈www.museu.ufrgs.br/admin/artigos/arquivos/NarradoresJave.doc $>$ Acesso em $31 / 09 / 2010$.

BOSI, Eclea. 1999. Memória e Sociedade: lembranças de velhos. São Paulo: Companhia das Letras.

BRECHT, Bertold. s/d. Lendas, parábolas, crônicas, sátiras e outros poemas. Tradução de Paulo Quintela. $\quad$ Disponível em http://www.citador.pt/poemas.php?op=10\&refid=200810060312. Acesso em $12 / 12 / 2010$.

GAGNEBIN, Jeanne Marie. 1999. História e narração em Walter Benjamin. São Paulo: Perspectiva.

MACHADO, Roberto. 2009. Deleuze, a arte e a filosofia. Rio de Janeiro: Jorge Zahar. PESAVENTO, Sandra Jatahi. 2006. História \& literatura: uma velha-nova história. Nuevo Mundo Mundos Nuevos, Debates. Disponível em http://nuevomundo.revues.org/1560. Acesso em 12/12/2010.

SCARELI, Giovana. Santo Forte: a entrevista no cinema de Eduardo Coutinho. Tese (Doutorado em Educação). Faculdade de Educação. Universidade Estadual de 
Campinas.

2009.

Disponível

em

http://cutter.unicamp.br/document/?code=000446067. Acesso em 12/12/2010.

WERNECK, Alexandre. Narradores de Javé. Contracampo.

<http://www.contracampo.com.br/58/narradoresdejave.htm> Acesso em $31 / 08 / 2010$.

Data de Recebimento: 07/03/11

Data de Aprovação: 02/06/11 


\section{Para citar essa obra:}

SCARELI, Giovana. Imagi-nando multiplicidades entre-tempos/lugares: um olhar sobre o filme Narradores de Javé. RUA [online]. 2011, no. 17. Volume 1 - ISSN 1413-2109 Consultada no Portal Labeurb - Revista do Laboratório de Estudos Urbanos do Núcleo de Desenvolvimento da Criatividade http://www.labeurb.unicamp.br/rua/

Laboratório de Estudos Urbanos - LABEURB

Núcleo de Desenvolvimento da Criatividade - NUDECRI

Universidade Estadual de Campinas - UNICAMP

http://www.labeurb.unicamp.br/

Endereço:

Rua Caio Graco Prado, 70

Cidade Universitária “Zeferino Vaz" - Barão Geraldo

13083-892 - Campinas-SP - Brasil

Telefone/Fax: (+55 19) 3521-7900

Contato: http://www.labeurb.unicamp.br/contato 